\title{
ANÁLISIS ZOOARQUEOLÓGICO DE PARAPETOS EN LA MESETA DEL STROBEL (PROVINCIA DE SANTA CRUZ)
}

\author{
Juan Dellepiane*
}

Fecha de recepción: 17 de diciembre de 2020

Fecha de aceptación: 30 de abril de 2021

\section{RESUMEN}

Este trabajo presenta la primera información zooarqueológica sistemática para la meseta del Strobel. La totalidad del registro óseo presentado procede de excavaciones realizadas en estructuras de parapetos, sitios que exhiben una notable frecuencia en la región. El propósito de este trabajo es doble. En primer lugar, dado que la conservación ósea representa una problemática importante en la arqueología de la meseta, se busca distinguir, desde una perspectiva tafonómica, la existencia de sectores más y menos conservativos de evidencia ósea en el interior del área. En segundo lugar, se evalúan las estrategias de subsistencia implementadas en la meseta durante el Holoceno tardío con el objeto de discutir la presencia de variabilidad en el manejo de la fauna. Los resultados obtenidos indican que, si bien la ocupación de la meseta exhibe un marcado carácter logístico y/o estacional, las estrategias implementadas se caracterizan por el desarrollo de alternativas múltiples y diferentes modalidades en relación con la utilización de los recursos faunísticos.

Palabras clave: parapetos - zooarqueología - variabilidad-meseta del Strobel-Holoceno tardio

\section{ZOOARCHAEOLOGICAL ANALYSIS OF HUNTING BLINDS \\ IN THE STROBEL PLATEAU (SANTA CRUZ PROVINCE)}

\section{ABSTRACT}

This work presents the first systematic zooarchaeological information for the Strobel plateau. The bone record presented was retrieved from excavations made in hunting blinds, sites with a

\footnotetext{
* Consejo Nacional de Investigaciones Científicas y Técnicas, Instituto Nacional de Antropología y Pensamiento Latinoamericano. E-mail: juandelle09@ hotmail.com
} 
remarkable frequency in the region. The purpose of this work is twofold. First, since bone conservation represents a major problem for the archaeological studies of the plateau, to the objective is to distinguish, from a taphonomic perspective, the existence of more and less conservative sectors of bone evidence within the area. Second, the subsistence strategies adopted in the plateau during the Late Holocene will be assessed in order to discuss the presence of faunal management variability. The results indicate that although the plateau occupation exhibits a marked logistic and/ or seasonal character, the adopted strategies are characterized by the development of multiple alternatives and different modalities in relation to the use of faunal resources.

Keywords: hunting blinds - zooarchaeology - variability-Strobel plateau - Late Holocene

\section{INTRODUCCIÓN Y OBJETIVOS}

Las investigaciones arqueológicas llevadas a cabo en la meseta del Strobel cuentan con una larga trayectoria. Los primeros trabajos fueron realizados por Carlos Gradin en la década de 1950, quien destacó la elevada frecuencia de grabados rupestres, materiales líticos en superficie y estructuras de parapetos en el área (Gradin 1959-60 a y b). Luego de estos desarrollos iniciales, a partir del año 2001, comenzaron a llevarse a cabo investigaciones sistemáticas en la región, las cuales se continúan hasta la actualidad. De este modo, la meseta del Strobel se incorpora en un proyecto arqueológico de carácter regional cuyo objetivo general ha sido estudiar la relación entre las fluctuaciones climáticas y ecológicas ocurridas durante el Holoceno tardío y los cambios en los patrones de la movilidad, asentamiento, subsistencia y demografía de las sociedades cazadoras-recolectoras que habitaron estos ambientes durante este lapso. En el marco de estos desarrollos, fueron propuestas dos hipótesis generales en relación con el carácter y funcionamiento de la meseta en el pasado. Por un lado, se establece su utilización logística y/o estacional durante los últimos 2500 años AP y, por otro, se sugiere la presencia de un proceso de convergencia poblacional en el Strobel (Belardi y Goñi 2006; Goñi 2010; Re 2010; Re et al. 2017; Flores Coni 2018; Guichón 2018; Dellepiane 2019; entre otros).

Desde el inicio, el estudio de las representaciones rupestres se estableció como una de las principales líneas de evidencia analizadas (Re 2010; Goñi et al. 2014; Re et al. 2017; Guichón 2018; entre otros). Paralelamente, otras se fueron incorporando, entre las que se destacan los trabajos realizados en torno a la tecnología lítica, los parapetos y las ocupaciones históricas de la región (Goñi et al. 2014; Nuevo Delaunay 2015; Re et al. 2017; Flores Coni 2018, 2019; Dellepiane 2019; entre otros). Gradualmente, comenzaron a incrementarse las investigaciones arqueológicas en el área, diversificándose las temáticas y problemáticas abordadas. En este contexto, el estudio del registro zooarqueológico de la meseta del Strobel, como en otros plateaus basálticos, se vio relativamente relegado. A pesar de los esfuerzos realizados, no se lograba obtener una representación ósea considerable, ya sea por problemas tafonómicos o por circunstancias de muestreo. Cabe destacar que una parte importante de las excavaciones realizadas en el área fueron llevadas a cabo en sitios localizados en paredones rocosos. Bajo este marco general, el área fue caracterizada como un ambiente poco conservativo de evidencia ósea (Belardi et al. 2007). En los últimos años, este escenario empezó paulatinamente a cambiar gracias al desarrollo de excavaciones sistemáticas en decenas de estructuras de parapetos que comenzaron a otorgar resultados positivos, permitiendo recuperar una gran cantidad de elementos óseos (Dellepiane y Flores Coni 2016; Goñi et al. 2016; Re et al. 2017).

Los parapetos pueden ser definidos como estructuras de piedra, cuya técnica constructiva consiste en la acumulación directa de rocas formando una pared, sin la utilización de argamasa o mortero. Generalmente, se caracterizan por presentar formas circulares y semicirculares y estar localizados en proximidad a cuerpos de agua. Este tipo de sitio a cielo abierto ha sido reconocido 
en diferentes partes del mundo y en ambientes muy variados. Su funcionalidad ha sido vinculada tanto con el desarrollo de actividades de caza y obtención de recursos faunísticos como así también con posibles bases de sujeción de toldos y tipis (Malouf 1961; Binford 1978, 1991; Frison 1978; Lupo 2001; Dalton 2011).

Los resultados que serán presentados en este trabajo se establecen como la primera información zooarqueológica sistemática para la meseta del Strobel. Por este motivo, se identifican dos objetivos principales. En primer lugar, y debido a que el problema de la conservación ósea ha sido crucial en las mesetas, se propone determinar los procesos tafonómicos que han operado en la formación de los conjuntos. Este análisis busca derivar implicancias que permitan discutir la preservación ósea en una escala intramesetaria. En el marco de la problemática regional, se considera que este desarrollo representará un aporte para la distinción de sectores más y menos conservativos de evidencias zooarqueológicas. En segundo lugar, caracterizar las estrategias de utilización de los recursos faunísticos en cada uno de los sitios considerados; a los fines de ponderar la existencia de variabilidad en los patrones de subsistencia identificados en la meseta. Se buscará delinear tendencias generales en relación con el manejo de la fauna que permitan incorporar esta línea de evidencia en las discusiones regionales vinculadas con el uso logístico y/o estacional de la meseta, la existencia de variabilidad funcional en el interior del área y, en última instancia, las dinámicas del poblamiento humano de los sectores altos de la región. Ambas líneas de análisis representan un campo fructífero para el estudio de las ocupaciones humanas en las mesetas, generando un cúmulo de evidencia novedosa no disponible habitualmente en Patagonia centro-meridional.

\section{UBICACIÓN ESPACIAL, CARACTERÍSTICAS AMBIENTALES Y ANTECEDENTES ARQUEOLÓGICOS DE LA MESETA DEL STROBEL}

La meseta del Strobel se localiza en el departamento de Río Chico, en el centro-oeste de la provincia de Santa Cruz, Argentina (figura 1). Se trata de una meseta basáltica miocénica que cubre un área de $2.500 \mathrm{~km}^{2}$, y limita hacia el norte y el este con el valle del río Chico, al oeste con la meseta de la Muerte y en dirección sur con la cuenca del lago Cardiel. Una de las características más destacables del área es la importante cantidad de cuerpos de agua que presenta, que alcanzan un total aproximado de 2.000 lagunas durante los años más húmedos (Lancelotti 2009). Esta configuración hídrica, sumada al lago Strobel y a otros cauces menores, representa un importante reservorio de agua para toda la región.

El clima predominante es templado-frio con una temperatura anual media entre $8^{\circ} \mathrm{C} \mathrm{y} 10^{\circ} \mathrm{C}$ (Paruelo et al. 1998). El área manifiesta un marcado gradiente de precipitaciones que oscila entre 200-400 mm anuales. Las bajas temperaturas y la altura sobre el nivel del mar (1.200 m s.n.m, en su sector más occidental) generan una importante carga de nieve que dificulta su habitabilidad durante el otoño/invierno. Así, este sector exhibe una marcada estacionalidad, responsable de las importantes fluctuaciones en el aporte hídrico. Con la llegada de la primavera y el verano se percibe un incremento excepcional de su productividad primaria en términos de oferta de nuevas pasturas, jerarquizándose regionalmente. Durante este lapso, la meseta es intensamente ocupada por tropillas de guanacos (Lama guanicoe) que aprovechan estos picos estacionales de productividad vegetal. Es en este período cuando se produce la época de parición de esta especie en el centro-oeste de la provincia de Santa Cruz.

En el interior de la meseta se reconoce una variedad de sectores topográficos y geomorfológicos que presentan características ambientales particulares. Se destacan: las superficies de pampas planas, los bajos con lagunas enmarcadas por paredones basálticos y, por último, el cañadón del río Barrancoso. Las mejores condiciones de reparo natural se localizan en los dos últimos. 


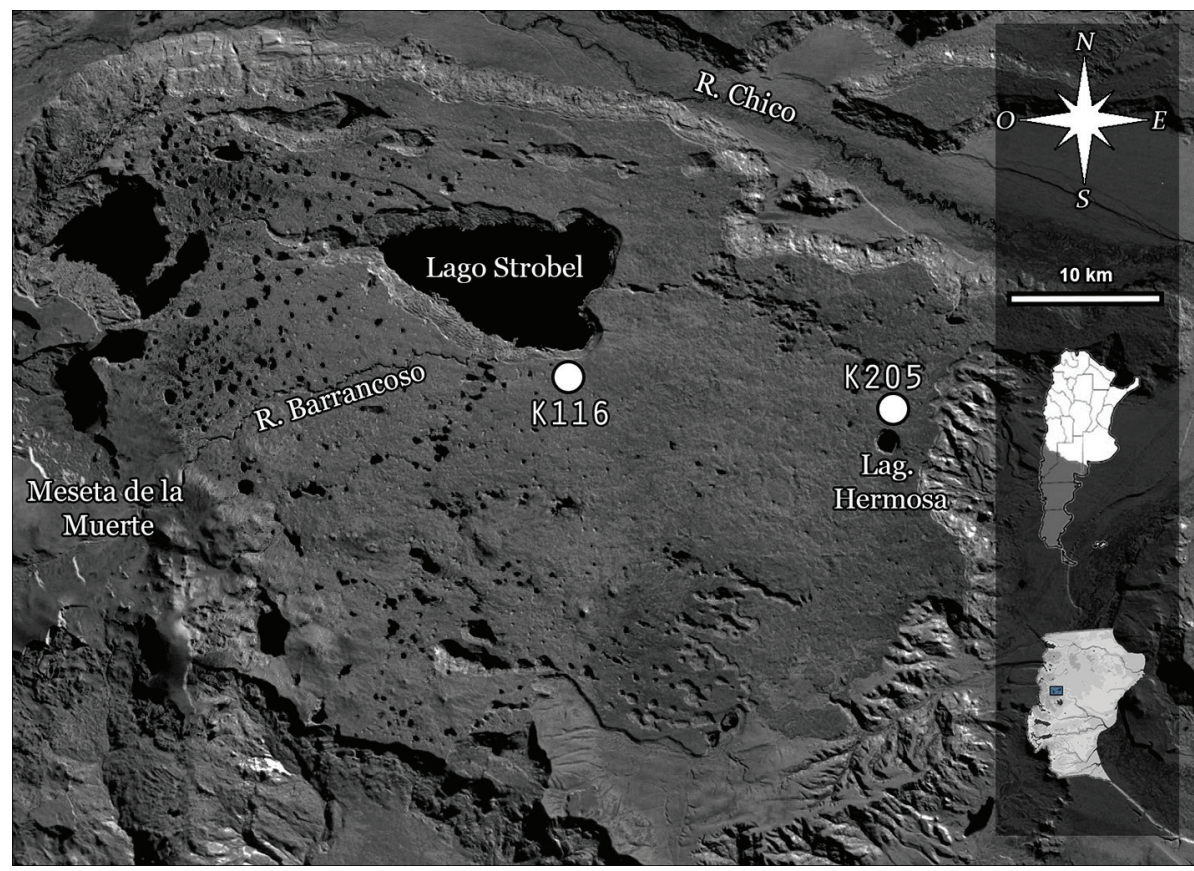

Figura 1. Ubicación espacial de la meseta del Strobel y localización de los sitios.

Referencias: R: Río; Lag: Laguna

En términos fitogeográficos, se encuentra dentro del Dominio Andino, Provincia Patagónica, Distrito Central, subdistrito austral o santacrucense (León et al. 1998). La vegetación constituye la expresión de la máxima aridez de las estepas patagónicas dada su fisonomía yerma y extremadamente xérica. La composición faunística de la región se conforma por especies características de la estepa: guanaco (Lama guanicoe), carnívoros como zorros (Dusycion sp.) y pumas (Felis concolor), edentados (Chaetophractus villosus, Zaedyus pichiy), roedores (Ctenomys sp., entre otros), y una gran variedad de lagartijas o matuastos. También se observa una numerosa avifauna, entre la que se destaca cauquén (Chloephaga picta), macáes (Podiceps gallardoi), flamencos (Phoenicopterus chilensis), y bandurrias (Theristicus caudatus). El ñandú petiso o choique (Rhea pennata) resalta en este contexto como la única ave corredora.

Las investigaciones arqueológicas llevadas a cabo en la mesorregión (sensu Dincauze 2000) establecen que la ocupación de los espacios en el pasado ha sido dependiente de los cambios climáticos/ambientales acaecidos durante el Holoceno, especialmente aquellos ocurridos en los últimos 2500 años AP (Goñi 2010). Durante este período se advierte una tendencia hacia el descenso de la humedad relativa (Stine y Stine 1990) que habría alcanzado su punto máximo hacia los 900 años AP durante la Anomalía Climática Medieval (Stine 1994). Bajo este escenario, nuevas condiciones ecológicas se definen, caracterizadas por una distribución heterogénea del agua, la liberación de nuevos espacios y una configuración ambiental en donde la estepa comienza a ocupar una mayor parte del paisaje.

En este contexto, se habría evidenciado un uso diferencial de los espacios en la región en relación con su ubicación altitudinal, jerarquizándose en función de su productividad primaria (Goñi 2010). Los sectores altos, como la meseta del Strobel habrían sido articulados logística y/o estacionalmente a partir de un proceso de extensificación (sensu Binford 2001; Goñi 2010), desde las cuencas bajas, caracterizadas por una utilización de carácter más residencial (Goñi y Barrientos 2004; Goñi 2010; Cassiodoro 2011, entre otros). Se propone entonces una marcada 
tendencia hacia un uso diferencial y complementario de espacios bajos y altos en función de la estructura de recursos disponibles en cada uno (Goñi 2010).

Concretamente, para la meseta del Strobel la información arqueológica disponible señala que este habría sido un espacio utilizado logística y/o estacionalmente por los grupos humanos que la habitaron en los últimos 2500 años AP. En este marco, el desarrollo de actividades extractivas asociadas con la caza de recursos faunísticos y el procesamiento inicial de presas habrían sido prioritarias. Adicionalmente, habría jugado un rol privilegiado dentro del circuito regional de interacción social, en especial en cuanto al intercambio de información (Belardi y Goñi 2006; Goñi 2010; Re 2010; Goñi et al. 2014; Re et al. 2017; Guichón 2018).

En referencia a la cronología, la tendencia de ocupación para el área se concentra en el Holoceno tardío, principalmente en los últimos 1300 años AP. No obstante, existen evidencias correspondientes a momentos previos (Goñi 2010; Re 2010; Goñi et al. 2014; Re et al. 2017; Flores Coni 2018; Guichón 2018). La meseta del Strobel habría sido un espacio totalmente incorporado a las dinámicas poblacionales de la región a partir de los 2500 años AP. Durante el Holoceno medio, su ocupación habría sido sólo esporádica, vinculada con las primeras etapas de colonización de estos espacios (Goñi 2010; Re 2010; Re et al. 2017; Flores Coni 2018; Guichón 2018; Dellepiane 2019). Cabe señalar que las cronologías más antiguas registradas en estructuras de parapetos, fechadas en $c a$. 2000 años AP, provienen de sitios ubicados en la Pampa del Asador (Cassiodoro 2011).

El análisis tecnológico de la evidencia lítica recuperada en la meseta del Strobel indica la existencia de una baja variabilidad artefactual, entre la que se destaca la gran cantidad de puntas de proyectil confeccionadas en obsidiana junto con la presencia de raspadores tanto en esta materia prima como en sílice (Goñi et al. 2014; Re et al. 2017; Flores Coni 2018). En los últimos años, los trabajos realizados han identificado diferencias entre la composición de los conjuntos líticos de parapetos y de paredones basálticos, que permiten sugerir el desarrollo de actividades diferenciales en el interior de la meseta (síntesis en Flores Coni 2018). Por otra parte, en referencia a la tecnología de parapetos, hasta la actualidad suman 368 las estructuras halladas $(\operatorname{Re} e t$ al. 2017; Flores Coni 2018). Adicionalmente, mediante el uso de herramientas de teledetección, 62 nuevas estructuras han sido registradas (Dellepiane 2018). Se destaca la variabilidad identificada en cuanto a su emplazamiento, morfología, dimensiones y registro asociado (Goñi et al. 2014; Flores Coni 2018).

El estudio de las representaciones rupestres ha sido una de las principales líneas de evidencia analizada desde el inicio de las investigaciones en la meseta del Strobel. En función de la alta frecuencia y diversidad de motivos grabados, junto con la tecnología de equipamiento espacial, se ha sugerido la presencia de un proceso de convergencia poblacional en la meseta, donde se concentraría y distribuiría información en una escala suprarregional (Belardi y Goñi 2006; Goñi 2010; Re 2010; Re et al. 2017; Guichón 2018; entre otros).

Hasta hace algunos años la presencia de restos faunísticos en la meseta presentaba muy baja frecuencia. Las excavaciones llevadas a cabo en sitios arqueológicos ubicados en paredones basálticos otorgaban resultados negativos. De acuerdo con Belardi y coautores (2007), el potencial de preservación de huesos en paredones rocosos de mesetas altas es bajo debido a las características químicas de los sedimentos ( $p h$ ácido) y a la alternancia de humedad que se produce como consecuencia de las grandes acumulaciones de nieve durante el invierno. A partir del año 2014, mediante el desarrollo de excavaciones sistemáticas en estructuras de parapetos se han logrado obtener las primeras muestras óseas de la región. Actualmente, el conocimiento zooarqueológico disponible deriva de la presentación y análisis preliminar del sitio K116 (Dellepiane y Flores Coni 2016; Goñi et al. 2016; Re et al. 2017). Las investigaciones llevadas a cabo en este sitio han sugerido el desarrollo de actividades vinculadas con la caza y el procesamiento de presas (Dellepiane y Flores Coni 2016; Goñi et al. 2016). 


\section{MUESTRA}

La muestra ósea considerada en este trabajo fue recuperada en dos sitios localizados en diferentes sectores de la meseta del Strobel (figura 1). Como se detallará a continuación, cada uno de ellos exhibe características particulares y se compone de un número variable de estructuras de parapetos. En esta oportunidad será presentada toda la información faunística disponible hasta la actualidad de ambos sitios, la cual procede de cuatro estructuras en el sitio K116 y de dos en K205. A continuación, se describen las características de ambos sitios.

\section{Sitio $K 116$}

Se localiza en la porción central de la meseta, próximo a la costa sureste del lago Strobel. Es un sitio destacado regionalmente dado que se compone de 54 parapetos, ubicados en un área de $0,4 \mathrm{~km}^{2}$ y distribuidos en una extensa pampa sin asociación directa con lagunas, mallines o cursos de agua, al menos actualmente (figura 2). El sitio cuenta con cinco fechados radiocarbónicos que indican una cronología en torno a los 1000 años AP (tabla 1). Esta información ha permitido sugerir el uso simultáneo de algunas de sus estructuras en el marco del desarrollo de estrategias de caza que pudieron incluir modalidades de tipo comunal y/o masiva (Dellepiane y Flores Coni 2016; Goñi et al. 2016; Re et al. 2017; Flores Coni 2019; Dellepiane 2019).

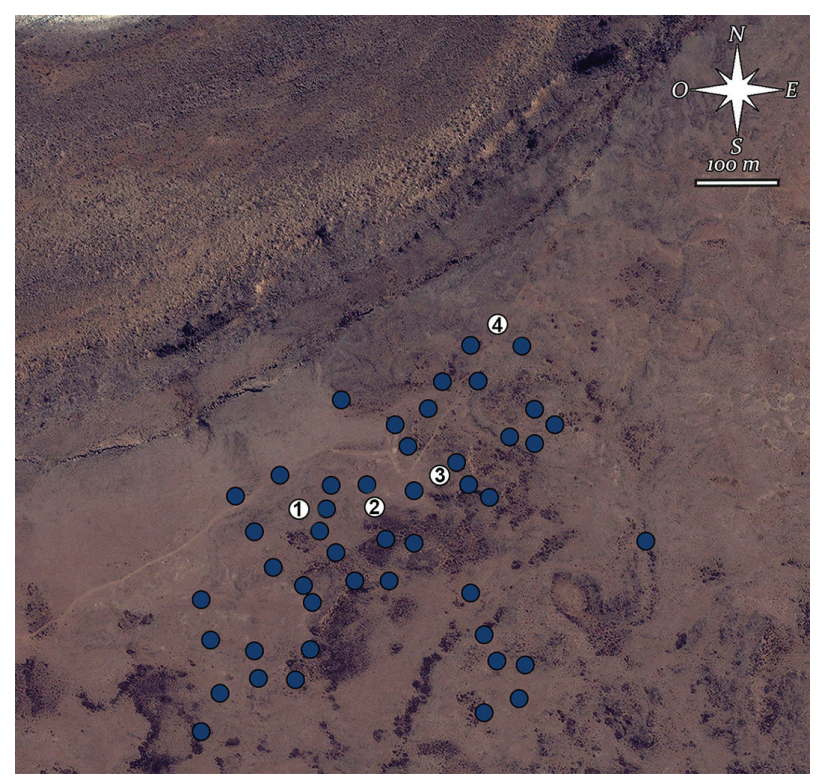

Figura 2. Esquema sitio K116: 1: parapeto 11; 2: parapeto 24; 3: parapeto 27; y 4: parapeto 38

Los trabajos llevados a cabo en el sitio K116 incluyeron recolecciones superficiales y excavaciones estratigráficas. Estas últimas fueron planificadas en aquellos parapetos que presentaban una alta frecuencia de materiales en superficie y que exhibían, fundamentalmente, restos zooarqueológicos (tabla 1). Dado que los elementos óseos se ubican entre o por debajo de las rocas que conforman la estructura, la metodología consistió en despedrar un sector de la pared del parapeto y establecer allí la excavación (Goñi et al. 2016) (figura 3.a). La disposición de las cuadrículas y la superficie excavada fue variable en cada caso, dependiendo de una serie de factores: la fre- 
cuencia de hallazgos, las características propias de cada estructura, la presencia de sedimento y las irregularidades del terreno. Si bien se realizaron sondeos en la mayoría de las estructuras que conforman el sitio, únicamente en los parapetos 11, 24 y 38 se logró recuperar una muestra ósea importante en estratigrafía (tabla 1). En cada conjunto se excavaron tres niveles artificiales de 10 $\mathrm{cm}$, hasta alcanzar el sustrato basáltico de base. Cabe señalar que no fueron reconocidos hiatos estratigráficos en los depósitos excavados. De este modo, dado que no fueron registradas diferencias en la composición estratigráfica de los sedimentos ni en las características y distribución del registro zooarqueológico, se consideran los niveles como un único bloque. Es importante mencionar que, junto con las anteriores, en este trabajo se incluye también la estructura 27 cuyos restos faunísticos proceden únicamente de superficie. Su inclusión responde al interés de presentar toda la información zooarqueológica del sitio disponible hasta la actualidad.

Tabla 1. Sitio K116: características generales, cronología y muestra ósea considerada

\begin{tabular}{|c|c|c|c|c|c|c|c|}
\hline K 116 & $\begin{array}{c}\text { Cuerda } \\
(\mathbf{m})\end{array}$ & $\begin{array}{c}\text { Profundidad } \\
(\mathbf{m})\end{array}$ & $\begin{array}{c}\text { Altura } \\
\text { máxima } \\
(\mathbf{m})\end{array}$ & $\begin{array}{c}\text { Superficie } \\
\text { excavada } \\
\left(\mathbf{m}^{2}\right)\end{array}$ & $\begin{array}{c}\text { Muestra } \\
\text { total }(\mathbf{n})\end{array}$ & $\begin{array}{c}\text { Cronología } \\
(\mathbf{a n ̃ o s} \text { AP) }\end{array}$ & Referencia \\
\hline Parapeto 11 & 5,4 & 4,1 & 0,7 & 7 & 635 & $976 \pm 47$ & $\operatorname{Re}$ et al. 2017 \\
\cline { 6 - 9 } & & 1 & 0,65 & 1 & 277 & $972+35$ & $\operatorname{Re}$ et al. 2017 \\
\hline Parapeto 24 & 2,7 & 3,15 & 0,8 & - & 145 & $1079 \pm 42$ & $\operatorname{Re}$ et al. 2017 \\
\hline Parapeto 27 & 6,8 & 1,6 & 0,6 & 1 & 556 & $1052 \pm 48$ & $\operatorname{Re}$ et al. 2017 \\
\hline Parapeto 38 & 3 & - & - & - & 1613 & & \\
\hline Total & - & - & & & & \\
\hline
\end{tabular}
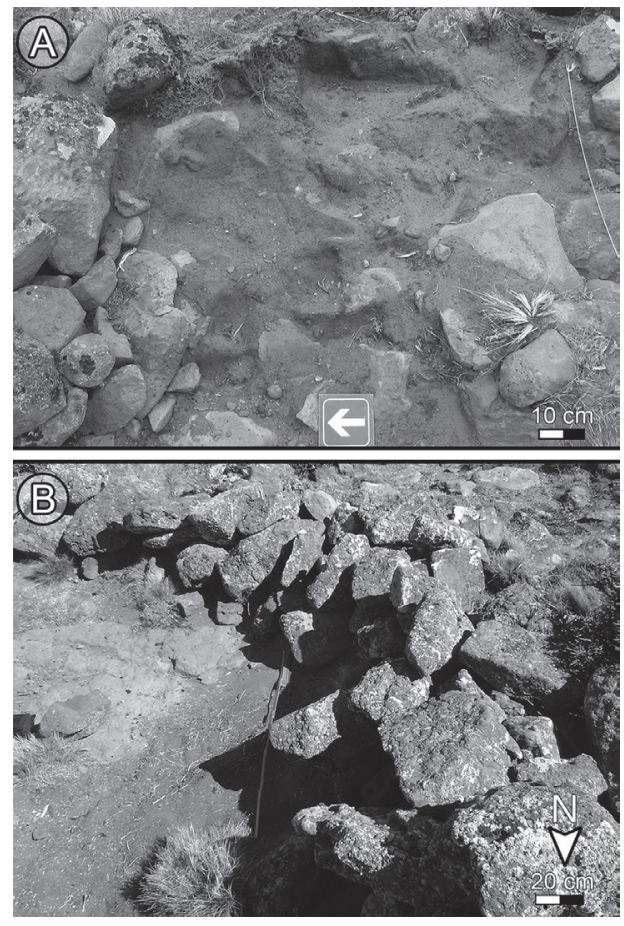

Figura 3. Sitios K116 y K205. (A) Excavación del parapeto 11 de K116. (B) Vista del parapeto 6 de K205 


\section{Sitio K205}

El sitio K205 comprende un conjunto de 10 parapetos que se encuentran ubicados en la porción este de la meseta del Strobel. Las estructuras se emplazan sobre una planicie con escasas ondulaciones y se localizan a $250 \mathrm{~m}$ de distancia de la Laguna Hermosa, uno de los principales cuerpos de agua en este sector de la meseta (figura 4). Los parapetos se destacan por sus grandes dimensiones, con paredes conformadas por una gran cantidad de rocas, constituidas, en la mayoría de los casos, por más de una hilera de piedras (figura 3.b). Exceptuando el parapeto 10, cuya forma es circular, las restantes nueve estructuras presentan una morfología de arco. Asociados a estas estructuras, a una distancia aproximada de $200 \mathrm{~m}$ en dirección norte y noreste, se localizan otros parapetos muy similares, pero que aún no han sido excavados. Es posible que estos conjuntos formen parte de un único sitio.

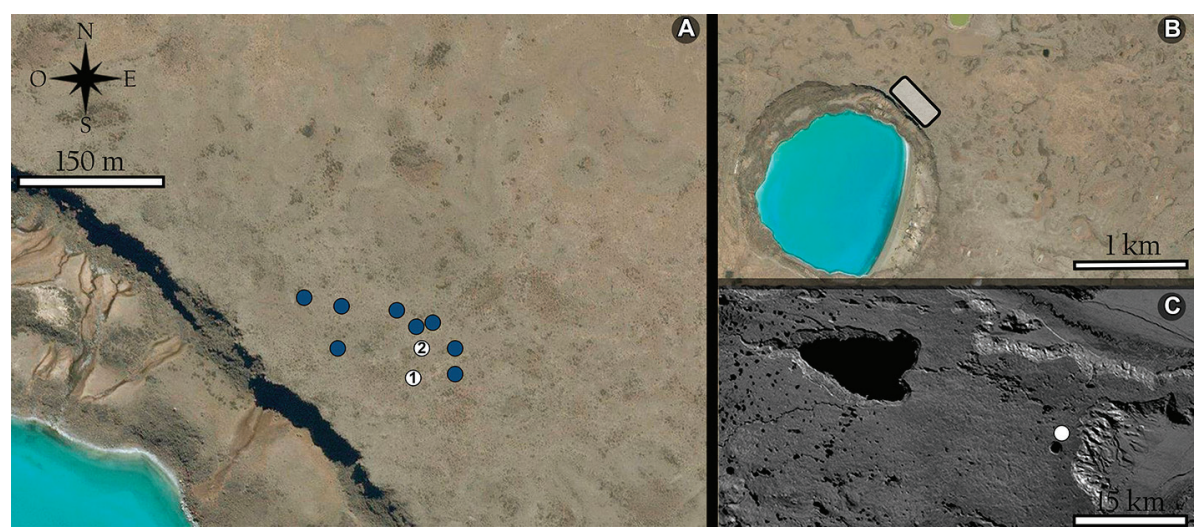

Figura 4. Esquema sitio K 205: (A) Esquema: 1: parapeto 10; 2: parapeto 6. (B) Relación espacial entre el sitio y la laguna Hermosa. (C) Ubicación del sitio en la meseta del Strobel

Se han obtenido tres fechados radiocarbónicos sobre muestras óseas de guanaco recuperadas en los parapetos 2 (superficie), 6 (estratigrafía) y 10 (estratigrafía). Los resultados enmarcan las ocupaciones en el Holoceno tardío (tabla 2). Como se detalla en la tabla 2, las edades indican distintos momentos de ocupación del sitio.

En este sitio se llevaron a cabo tanto recolecciones superficiales como excavaciones. Las primeras se realizaron en todas las estructuras, incluyendo los sectores entre las rocas que conforman la pared. Se recuperaron materiales líticos y óseos en la mayoría de ellas. Las excavaciones se efectuaron en los parapetos 6, 10 y 4. Hasta el momento, únicamente en los dos primeros ha sido posible recuperar una muestra importante de restos óseos. Por lo tanto, solo estos serán considerados en este trabajo.

Tabla 2. Sitio K205: características generales, cronología y muestra ósea considerada

\begin{tabular}{|c|c|c|c|c|c|c|c|}
\hline K 205 & $\begin{array}{c}\text { Cuerda } \\
(\mathbf{m})\end{array}$ & $\begin{array}{c}\text { Profundidad } \\
(\mathbf{m})\end{array}$ & $\begin{array}{c}\text { Altura } \\
\mathbf{m a ́ x i m a} \\
(\mathbf{m})\end{array}$ & $\begin{array}{c}\text { Superficie } \\
\text { excavada } \\
\left(\mathbf{m}^{\mathbf{2}}\right)\end{array}$ & $\begin{array}{c}\text { Muestra } \\
\text { total (n) }\end{array}$ & $\begin{array}{c}\text { Cronología } \\
(\mathbf{a n ̃ o s ~ A P )}\end{array}$ & Referencia \\
\hline Parapeto 2 & & & & 0 & 0 & $273 \pm 23$ & Flores Coni 2019 \\
\hline Parapeto 6 & 4,48 & 2,47 & 0,81 & 2,252 & 712 & $364 \pm 27$ & $\begin{array}{c}\text { Cassiodoro } \text { et al } \text {. } \\
2019\end{array}$ \\
\hline Parapeto 10 & 5,08 & 3,61 & 1 & 2,342 & 273 & $1648 \pm 28$ & Flores Coni 2019 \\
\hline Total & - & - & - & - & 985 & - & - \\
\hline
\end{tabular}


Con respecto a la comparabilidad de los conjuntos óseos considerados, como se detalló en las tablas 1 y 2 , todas las muestras presentan un tamaño adecuado que permite establecer relaciones entre ellas. Adicionalmente, con el objeto de ponderar si las frecuencias de especímenes o de individuos se encontraban vinculadas con el tamaño de las muestras, fueron correlacionadas ambas variables con las superficies excavadas en cada parapeto. Los resultados señalan una ausencia de correlación estadística en ambos casos: $r s: 0,866-p: 0,1$ y $r s: 0,410-p: 0,5$, respectivamente.

\section{MÉTODOS}

En este trabajo se considera al espécimen como la unidad mínima de análisis y sobre la que se evalúan diferentes variables morfológicas (e.g., marcas y huellas) y cualitativas (e.g. meteorización, termoalteraciones). La determinación taxonómica y anatómica del material óseo fue realizada utilizando la colección comparativa del Instituto Nacional de Antropología y Pensamiento Latinoamericano junto con el uso de manuales osteológicos específicos (Pacheco Torres et al. 1979; Sierpe 2015).

La abundancia taxonómica fue estimada a partir de las medidas convencionales de NISP, NISP\% y MNI. Esta última, fue obtenida en función de la lateralidad, el estado de fusión y el tamaño de los huesos (Mengoni Goñalons 1999). La composición etaria de cada conjunto óseo fue evaluada a partir del porcentaje de especímenes (NISP) y elementos (MNE) inmaduros. La abundancia de partes anatómicas fue calculada en función del MNE, el MAU y el MAU \% (Binford 1978; Klein y Cruz-Uribe 1984; Lyman 1994). La representación esqueletaria reconstruida fue correlacionada estadísticamente (rho Spearman) con el Índice de Utilidad de Carne (Borrero 1990) modificado por Lyman (1994), el Índice de Médula Ósea (Mengoni Goñalons 1999), el Índice de Médula Insaturada (Morin 2007; Rindel 2013) y, finalmente, el Índice de Secado de Carne para camélidos (De Nigris y Mengoni Goñalons 2005).

En función de los valores de NISP y MNE obtenidos en cada conjunto óseo, fue estimada la relación existente entre el segmento axial y el apendicular para cada una de ambas medidas. Se tomó como referencia el valor sugerido por Mengoni Goñalons (1999) de 1,57 como resultado esperable. También fue estimada la integridad con la cual las carcasas ingresaron en cada sitio utilizando el índice de completitud anatómica y se midió la incidencia de la fragmentación ósea en los conjuntos a partir de la relación entre el NISP/MNE.

Por otra parte, se llevó a cabo un análisis tafonómico de los especímenes óseos. Las variables relevadas fueron: meteorización, acción de roedores y de carnívoros, de raíces y la depositación química (Behrensmeyer 1978; Binford 1981; Lyman 1994; Fisher 1995; Gutiérrez 2004; Gutiérrez et al. 2016; entre otros). En cuanto a la incidencia de procesos atricionales mediados por la densidad mineral ósea, se utilizó el índice propuesto por Elkin (1995).

Finalmente, se evaluó la presencia de evidencias de procesamiento. Las variables consideradas incluyen el tipo, distribución, orientación y frecuencia de huella de corte y el tipo de fractura (Mengoni Goñalons 1999). Para dar cuenta de la acción térmica sobre los elementos óseos, se utilizó un criterio macroscópico vinculado con la textura y coloración de estos (Mengoni Goñalons 1999).

\section{RESULTADOS}

\section{Composición Taxonómica}

La muestra total analizada es de 2.598 especímenes óseos, de los cuales aproximadamente el $66 \%(n=1.710)$ pudo ser identificado taxonómicamente. 
Relaciones de la Sociedad Argentina de Antropología 46 (1), enero-junio 2021: 313-337

Tabla 3. Composición taxonómica de los conjuntos zooarqueológicos

\begin{tabular}{|c|c|c|c|c|c|c|c|c|c|c|c|c|}
\hline & \multicolumn{2}{|c|}{ Parapeto 27 } & \multicolumn{2}{|c|}{ Parapeto 38 } & \multicolumn{2}{c|}{ Parapeto 11 } & \multicolumn{2}{|c|}{ Parapeto 24 } & \multicolumn{2}{|c|}{ Parapeto 6 } & \multicolumn{2}{|c|}{ Parapeto 10 } \\
\cline { 2 - 15 } & NISP & NISP\% & NISP & NISP\% & NISP & NISP\% & NISP & NISP\% & NISP & NISP\% & NISP & NISP\% \\
\hline Lama guanicoe & 88 & 60,7 & 414 & 74,5 & 403 & 63,5 & 116 & 41,9 & 484 & 68 & 196 & 72 \\
\hline $\begin{array}{c}\text { Chloephaga } \\
\text { picta }\end{array}$ & - & - & 1 & 0,2 & 3 & 0,5 & - & - & - & - & - & - \\
\hline Rhea pennata & - & - & - & - & 1 & 0,1 & - & - & - & - & - & - \\
\hline Zaedyus pichiy & - & - & - & - & - & - & - & - & 2 & 0,2 & & \\
\hline Felis concolor & - & - & 1 & 0,2 & 1 & 0,1 & - & - & - & - & - & - \\
\hline Indeterminados & 57 & 39,3 & 140 & 25,2 & 227 & 35,7 & 161 & 58,1 & 226 & 31,7 & 77 & 28 \\
\hline Total & 145 & 100 & 556 & 100 & 635 & 100 & 277 & 100 & 712 & 100 & 273 & 100 \\
\hline
\end{tabular}

Como se indica en la tabla 3, la presencia de guanaco en cada parapeto es dominante, configurando perfiles prácticamente monoespecíficos. En este sentido, el aporte de otros taxones se encuentra notablemente reducido a unos pocos fragmentos de choique, puma y cauquén en los parapetos 11 y 38, y dos placas de piche en el parapeto 6 (tabla 3). Cabe mencionar que en ninguno de ellos se registró evidencias de procesamiento. Este resultado sugiere una marcada estabilidad no solo en el aprovechamiento de una única presa, sino también en una escasa utilización de otras especies como complemento de nutrientes y recursos. Este es un aspecto interesante, porque se diferencia levemente de lo registrado en otros sectores altos de la región, próximos a la meseta del Strobel, en donde se observa que, si bien bajo una clara dependencia hacia el guanaco, se produce la incorporación de especies menores en la dieta (Rindel 2009; Dellepiane 2019). La escasa diversidad taxonómica registrada en el área puede estar vinculada a la incidencia de una serie de factores asociados con la disponibilidad ecológica local, la operatoria de procesos específicos de destrucción diferencial y el desarrollo de estrategias de caza dirigidas principalmente a la obtención de este ungulado.

\section{Número mínimo de individuos}

En referencia a las muestras óseas de guanaco, el número mínimo de individuos (MNI) registrado en cada estructura es variable (tabla 4).

Tabla 4. Número mínimo de individuos e información etaria de los conjuntos faunísticos

\begin{tabular}{|c|c|c|c|c|}
\hline Sitio & Estructura & MNI & \% Inmaduros NISP & \% Inmaduros MNE \\
\hline K116 & Parapeto 27 & 2 & 18 & 17,5 \\
\hline K116 & Parapeto 38 & 7 & 15,9 & 16,9 \\
\hline K116 & Parapeto 11 & 7 & 23,2 & 23 \\
\hline K116 & Parapeto 24 & 3 & 42,8 & 53 \\
\hline K205 & Parapeto 6 & 8 & 25,2 & 31,4 \\
\hline K205 & Parapeto 10 & 3 & 22,3 & 23,3 \\
\hline
\end{tabular}


De acuerdo con la información presentada en la tabla 4, es posible reconocer dos agrupaciones. Una conformada por los parapetos 11, 38 y 6, donde la cantidad mínima reconstruida es mayor; y otra compuesta por las estructuras restantes, caracterizada por una menor representación de animales registrados. Si bien estas diferencias pueden estar ligadas a discrepancias en el área de muestreo y/o a una mayor incidencia de procesos específicos de deterioro ambiental en algún caso puntual, también podrían indicar el desarrollo de diferentes estrategias de obtención de presas en la meseta a lo largo del tiempo y del espacio. Al respecto, los fechados radiocarbónicos obtenidos en las cuatro estructuras del sitio K116 han arrojado edades muy similares entre sí, ca. 1000 años AP y no presentan diferencias estadísticamente significativas (t 7,31 >0,05). Sobre la base de esta evidencia es posible sugerir el uso sincrónico de estos parapetos, al menos durante dicho período (Goñi et al. 2016; Re et al. 2017). Por lo tanto, si se considera esta información, la cantidad mínima de individuos registrados en el sitio podría ascender significativamente, alcanzado un MNI de 19 animales.

Por otra parte, en todos los parapetos ha sido posible registrar la presencia de individuos subadultos, en algunos casos en frecuencias elevadas (parapeto 24) (tabla 4). Dentro de este conjunto, se destaca la presencia de, al menos, un animal cría (menor a los 6 meses de edad) en cada parapeto. La selección de esta cohorte podría estar ligada al aprovechamiento de su cuero en tanto que otros recursos nutricionales son escasos o pobres en términos calóricos (De Nigris 2003). Este es un resultado consistente con el carácter estacional propuesto para el área y permite ubicar la ocupación de la meseta en algún momento durante el final de la primavera, el verano y/o el principio del otoño. El perfil reconstruido compuesto por guanacos crías, subadultos y adultos permite sugerir una predación preferencial sobre un segmento demográfico específico: grupos familiares. Cabe señalar que estas son las agrupaciones más estables y predecibles dentro de las poblaciones de guanacos. Los grupos familiares están compuestos por unidades sociales promediadas de 7 individuos, conformados por un macho adulto, hembras y sus juveniles, generalmente menores a los 15 meses de edad. Cada uno de estos grupos familiares presenta un territorio defendido y permanentemente ocupado por el macho adulto (Franklin 1982, 1983).

\section{Modificaciones producidas por agentes y procesos no humanos}

El análisis tafonómico ha permitido identificar la existencia de diferentes agentes y procesos que han operado, principalmente en baja magnitud, en la formación de los conjuntos óseos (tabla 5).

Tabla 5. Procesos y agentes tafonómicos identificados

\begin{tabular}{|c|c|c|c|c|c|c|c|c|c|c|c|c|}
\hline & \multicolumn{2}{|c|}{ Parapeto 27 } & \multicolumn{2}{|c|}{ Parapeto 38 } & \multicolumn{2}{c|}{ Parapeto 11 } & \multicolumn{2}{|c|}{ Parapeto 24 } & \multicolumn{2}{|c|}{ Parapeto 6 } & \multicolumn{2}{c|}{ Parapeto 10 } \\
\cline { 2 - 16 } & NISP & NISP\% & NISP & NISP\% & NISP & NISP\% & NISP & NISP\% & NISP & NISP\% & NISP & NISP\% \\
\hline Raíces & 3 & 4,3 & 87 & 23,0 & 32 & 8,2 & 18 & 15,7 & 70 & 15,9 & 40 & 22,5 \\
\hline Carnívoros & 1 & 1,4 & 1 & 0,3 & 5 & 1,3 & - & - & 6 & 1,4 & 10 & 5,6 \\
\hline Manganeso & 2 & 2,9 & - & - & 3 & 0,8 & - & - & 1 & 0,2 & - & - \\
\hline Roedores & 2 & 2,9 & 2 & 0,5 & 3 & 0,8 & 5 & 4,3 & 3 & 0,7 & - & - \\
\hline W0 & - & - & - & - & - & - & - & - & - & - & - & - \\
\hline W1 & 2 & 2,9 & - & - & 1 & 0,3 & - & - & - & - & - & - \\
\hline W2 & 8 & 11,6 & 82 & 21,7 & 149 & 38,4 & 21 & 18,4 & 61 & 13,9 & 17 & 9,6 \\
\hline W3 & 44 & 63,7 & 252 & 66,7 & 201 & 51,8 & 78 & 68,4 & 323 & 73,4 & 150 & 84,3 \\
\hline
\end{tabular}


Relaciones de la Sociedad Argentina de Antropología 46 (1), enero-junio 2021: 313-337

(Tabla 5. Continuación)

\begin{tabular}{|c|c|c|c|c|c|c|c|c|c|c|c|c|}
\hline & \multicolumn{2}{|c|}{ Parapeto 27 } & \multicolumn{2}{|c|}{ Parapeto 38 } & \multicolumn{2}{c|}{ Parapeto 11 } & \multicolumn{2}{c|}{ Parapeto 24 } & \multicolumn{2}{|c|}{ Parapeto 6 } & \multicolumn{2}{c|}{ Parapeto 10 } \\
\cline { 2 - 15 } & NISP & NISP\% & NISP & NISP\% & NISP & NISP\% & NISP & NISP\% & NISP & NISP\% & NISP & NISP\% \\
\hline W4 & 15 & 21,7 & 44 & 11,6 & 34 & 8,8 & 15 & 13,2 & 56 & 12,7 & 11 & 6,2 \\
\hline W5 & - & - & - & - & 3 & 0,8 & - & - & - & - & - & - \\
\hline Total & 69 & 100 & 378 & 100 & 388 & 100 & 114 & 100 & 440 & 100 & 178 & 100 \\
\hline
\end{tabular}

La meteorización es el agente que mayor incidencia manifiesta, afectando la totalidad de los elementos óseos recuperados en cada parapeto. En general, se observa un patrón muy similar entre todos los conjuntos considerados, caracterizado por una baja diversidad de estadios representados con una tendencia hacia el predominio de estadios maduros (2 y 3), cada uno con una incidencia variable en cada caso (tabla 5). La presencia de huesos en instancias de meteorización más avanzadas es baja, con frecuencias que, usualmente, no rebasan el 15\% del total del NISP. Solo en el parapeto 27 se observan valores levemente superiores, aspecto posiblemente vinculado con el contexto de recuperación de la muestra (superficie) (tabla 5).

Por otra parte, la acción de raíces ha sido registrada en todos los conjuntos óseos, aunque su incidencia es baja. Solo en los parapetos 38 y 10 se exhiben frecuencias superiores al 20\% (tabla 5). Las marcas identificadas tienen un desarrollo limitado que alteran de manera restringida el tejido cortical de los huesos. De todas formas, es posible que su operatoria junto con la de otros agentes tafonómicos (por ej. meteorización) hayan afectado la visibilidad de otras marcas naturales y/o antrópicas. Es interesante destacar la presencia de marcas de raíces en el parapeto 27, conjunto óseo que procede de superficie, que indican la existencia de cierta dinámica en las condiciones de enterramiento/reexposición de, al menos, una parte de su muestra. Con respecto a la actividad de roedores, como se observa en la tabla 5, presenta una escasa magnitud en cada parapeto y se encuentra ausente en la estructura 10. Los daños fueron identificados principalmente en huesos planos: costillas y procesos espinosos de vértebras, y también sobre bordes de fracturas ubicados en la diáfisis de huesos largos.

La presencia de marcas de carnívoros fue registrada en la mayoría de los conjuntos (tabla 5). En general, las frecuencias obtenidas son muy bajas y no superan el $2 \%$ del total del NISP en cada estructura, con excepción de lo registrado en el parapeto 10. Los daños identificados se corresponden con pits y punctures localizados en elementos óseos de la columna vertebral, articulaciones de huesos largos y falanges; y crenuleted edge registrados sobre escápulas y pelvis. Como puede observarse, las marcas se ubican en huesos que, luego de su descarte, pueden conservar una elevada disponibilidad de remanentes nutricionales (grasa medular intraósea). Por otra parte, la presencia de alteraciones producidas por óxido de manganeso solo ha sido registrada en tres estructuras (parapetos 27, 11 y 6) y en muy baja frecuencia (tabla 5). En general, se presentan como pequeñas manchas negras/negras azuladas, aisladas y de pequeñas dimensiones, localizadas en la superficie del hueso. Su operatoria indica la existencia de condiciones de humedad en la formación de los conjuntos, posiblemente vinculada con la acumulación de nieve sobre la pared de las estructuras.

\section{Representación de partes anatómicas}

En todos los parapetos se registra una preponderancia del esqueleto apendicular por sobre el axial (tabla 6). Este último exhibe una subrepresentación muy marcada en la mayoría de los casos, especialmente en los parapetos 27 y 10 . Solo en la estructura 24 se registra que este desbalance anatómico es menor. No obstante, el patrón general es claro y se corresponde con la tendencia 
general sugerida para el registro zooarqueológico recuperado en Patagonia meridional (Mengoni Goñalons 1999; De Nigris 2003; De Nigris y Mengoni Goñalons 2004; Rindel 2009, entre otros). Cabe mencionar que estos resultados se mantienen, independientemente de la medida utilizada para su cálculo (NISP o MNE), indicando que no se encuentran sujetos al grado de fragmentación de los conjuntos (tabla 6).

Tabla 6. Medidas anatómicas

\begin{tabular}{|c|c|c|c|c|c|c|}
\hline & $\begin{array}{c}\text { Parapeto } \\
\mathbf{2 7}\end{array}$ & $\begin{array}{c}\text { Parapeto } \\
\mathbf{3 8}\end{array}$ & $\begin{array}{c}\text { Parapeto } \\
\mathbf{1 1}\end{array}$ & $\begin{array}{c}\text { Parapeto } \\
\mathbf{2 4}\end{array}$ & $\begin{array}{c}\text { Parapeto } \\
\mathbf{6}\end{array}$ & $\begin{array}{c}\text { Parapeto } \\
\mathbf{1 0}\end{array}$ \\
\hline $\begin{array}{c}\text { Relación Axial/ } \\
\text { Apendicular: NISP }\end{array}$ & 0,17 & 0,27 & 0,31 & 0,82 & 0,31 & 0,40 \\
\hline $\begin{array}{c}\text { Relación Axial/ } \\
\text { Apendicular: MNE }\end{array}$ & 0,27 & 0,23 & 0,21 & 0,60 & 0,24 & 0,17 \\
\hline C. Anat. Global* & 17,70 & 21,29 & 21,57 & 15,71 & 24,52 & 20,00 \\
\hline C. Anat. Axial** & 8,00 & 7,60 & 8,76 & 10,22 & 12,50 & 6,00 \\
\hline C. Anat. Apendicular*** & 32,10 & 41,50 & 40,48 & 23,81 & 42,20 & 40,00 \\
\hline $\begin{array}{c}\text { Índice de Fragmentación } \\
\text { Global **** }\end{array}$ & 1,57 & 1,89 & 1,90 & 1,60 & 1,47 & 1,59 \\
\hline $\begin{array}{c}\text { Índice de Fragmentación } \\
\text { Axial }\end{array}$ & 1,30 & 2,66 & 2,40 & 1,89 & 1,74 & 2,82 \\
\hline $\begin{array}{c}\text { Índice de Fragmentación } \\
\text { Apendicular**** }\end{array}$ & 1,67 & 1,71 & 1,70 & 1,30 & 1,38 & 1,30 \\
\hline
\end{tabular}

Referencias: *excluye hioides, carpianos, tarsianos, caudales y sesamoideos; **excluye caudales, carpianos, tarsianos, rótulas y sesamoideos; $* * *$ excluye hioides y caudales; $* * * *$ excluye carpianos, tarsianos, rótulas y sesamoideos; *****fueron excluidos elementos enteros: tarsianos, carpianos, sesamoideos, astrágalos.

Por otra parte, la integridad anatómica de las carcasas recuperadas en cada parapeto es baja (tabla 6). Los valores obtenidos ocupan un rango que oscila entre un $15 \%$ y un $25 \%$, distribución que también indica el reducido grado de variación presente. La completitud del esqueleto axial es especialmente baja, en promedio menor al 9\%. Los valores máximos y mínimos se registran en el parapeto 6 y 10, respectivamente. En referencia al segmento apendicular, su integridad es más moderada y exhibe una tendencia un tanto más heterogénea. De este modo, se reconoce un grupo con valores próximos al 40\% (parapetos 11, 38, 6 y 10) y otro, con frecuencias menores, conformado por las estructuras 27 y 24 correspondientes al sitio K116. La fragmentación ósea, principalmente global y apendicular, manifiesta una reducida incidencia; con un leve incremento para el segmento axial, especialmente en las estructuras 38, 10 y 11 (tabla 6).

De acuerdo a la información descripta en la figura 5, exceptuando los parapetos 27 y 24, en los restantes conjuntos la mayoría de los elementos o porciones óseas se encuentran presentes. Las frecuencias obtenidas para especímenes correspondientes al segmento axial son, en general, bajas-moderadas. En este marco, los valores de MAU\% más elevados se registraron para el cráneo (parapetos 11, 24 y 10), el sacro (parapeto 6), la pelvis (parapeto 38) y las vértebras torácicas en el parapeto 27. Comparativamente, algunas categorías óseas, especialmente costillas y columna, exhiben una distribución muy similar entre todos los conjuntos. En referencia a esta última, manifiesta una tendencia bastante clara en todos los casos hacia una mayor presencia de vértebras 
cervicales, especialmente procesos craneales/caudales, seguidas por torácicas y, finalmente, lumbares. El parapeto 24 mantiene este patrón general, pero con frecuencias significativamente más elevadas, aspecto que lo distingue del resto. Por su parte, las costillas están pobremente representadas en todas las estructuras. La presencia de pelvis es un tanto más variable, hallándose bien representada en los parapetos 38 y 24, pero ausente en los parapetos 27 y 11. En K205 su presencia es baja y similar en ambos conjuntos.

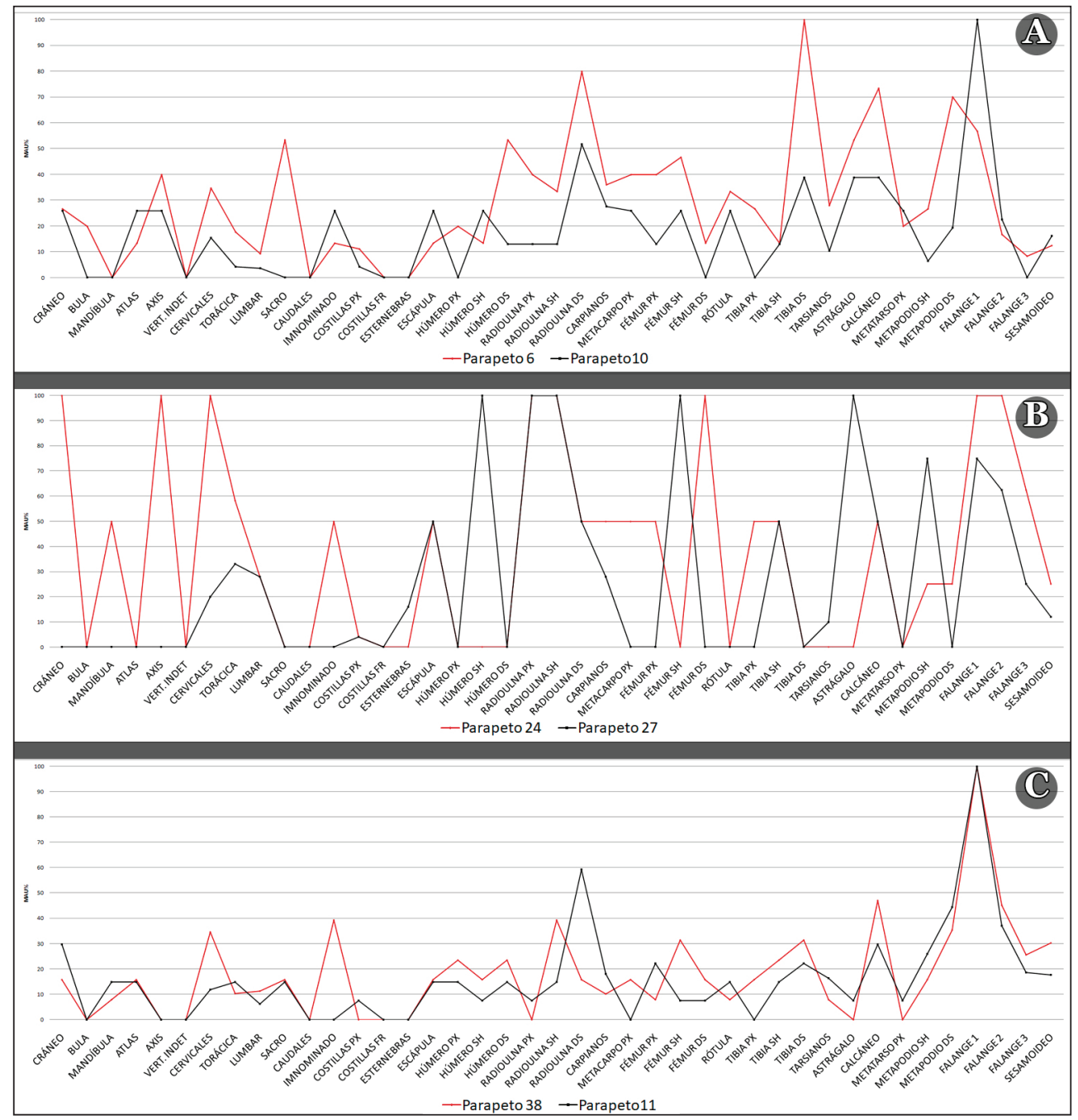

Figura 5. Representación de partes esqueletarias (MAU\%) (A): parapetos 6 y 10 (sitio K205); (B): parapetos 24 y 27 (sitio K116) y (C) parapetos 38: y 11 (sitio K116)

Con respecto al esqueleto apendicular, en general se evidencia una distribución más variable y heterogénea entre los conjuntos. No obstante, como tendencia global, las falanges primeras y extremidades, principalmente medias, suelen presentar las frecuencias más elevadas. Los parapetos 11 y 38 exhiben un perfil equilibrado, especialmente este último, caracterizado por la presencia de la mayor parte de las categorías óseas en proporciones bajas-moderadas. En ambos casos, las falanges primeras dominan cada conjunto, seguidas por calcáneos y articulaciones medias: ra- 
dioulna distal y tibia distal respectivamente. El manejo del segmento apendicular es muy similar en ambas estructuras. Por otra parte, la representación de partes en los parapetos 24 y 27 es un tanto más compleja, incompleta, determinada por ausencias y especímenes con valores muy altos de MAU\%. En este marco, en el primero se destacan falanges primeras y segundas, fragmentos proximales y diáfisis de radioulna y extremos distales de fémur. Por otra parte, el perfil reconstruido en el parapeto 27 focaliza en los huesos largos, fundamentalmente diáfisis, calcáneos y falanges. Se debe mencionar que, con excepción de algunos casos, se registra en esta estructura una ausencia de epífisis.

En el sitio K205, el parapeto 10 exhibe una distribución relativamente similar a la descripta para las estructuras 11 y 38. Es decir, en promedio, frecuencias bajas-moderadas para todo el segmento, destacándose la presencia de falanges primeras y en menor medida, articulaciones distales de radioulna y tibia. El perfil reconstruido para el parapeto 6 sugiere la presencia de algunas diferencias. En general, las frecuencias obtenidas son más elevadas, especialmente para huesos largos, astrágalos y calcáneos, mientras que la importancia de falanges primeras se encuentra más reducida. Si bien las extremidades medias presentan los valores más altos, húmero, fémur, metacarpos y metatarsos también manifiestan una buena representación. Nuevamente, predominan articulaciones, principalmente distales.

Tabla 7. Correlaciones estadísticas

\begin{tabular}{|l|c|c|c|c|c|}
\hline & DMO & MAU\% $:$ IS $* *$ & MAU\% : IC $* * *$ & $\begin{array}{c}\text { MAU\% : } \\
\text { IM } * * * *\end{array}$ & $\begin{array}{c}\text { MAU\%: } \\
\text { UMI***** }\end{array}$ \\
\hline Parapeto 27 & $\mathbf{0 , 4 0 4 1} \boldsymbol{p} \mathbf{0 , 0 1}$ & $\mathbf{- 0 , 6 2 3 4} \boldsymbol{p} \mathbf{0 , 0 2}$ & $0,4937 p 0,3$ & $0,2468 p 0,66$ & $0,1317 p 0,6$ \\
\hline Parapeto 38 & $0,2368 p 0,16$ & $\mathbf{- 0 , 6 1 4 3} \boldsymbol{p} \mathbf{0 , 0 , 2}$ & $-0,7247 p 0,12$ & $-0,7537 p 0,11$ & $0,1997 p 0,51$ \\
\hline Parapeto 11 & $0,2055 p 0,22$ & $\mathbf{- 0 , 7 4 1 4} \mathbf{0 , 0 0 3}$ & $-0,7247 p 0,12$ & $-0,7537 p 0,11$ & $0,102 p 0,74$ \\
\hline Parapeto 24 & $-0,0891 p 0,60$ & $\mathbf{- 0 , 1 3 2 4} \boldsymbol{p} \mathbf{0 , 6 6}$ & $\mathbf{0 , 0 3} \boldsymbol{p} \mathbf{1}$ & $\mathbf{- 0 , 0 3} \boldsymbol{p} \mathbf{1}$ & $0,310 p 0,30$ \\
\hline Parapeto 6 & $0,306 p 0,06$ & $\mathbf{- 0 , 6 4} \boldsymbol{p} \mathbf{0 , 0 1}$ & $-0,487 p 0,29$ & $-0,2 p 0,65$ & $0,437 p 0,13$ \\
\hline Parapeto 10 & $\mathbf{0 , 5 0 0} \boldsymbol{p} \mathbf{0 , 0 0 1}$ & $\mathbf{- 0 , 7 6 2 7} \boldsymbol{p} \mathbf{0 , 0 0 2}$ & $-0,394 p 0,45$ & $-0,516 p 0,33$ & $0,292 p 0,33$ \\
\hline
\end{tabular}

Referencias: *Índice de Densidad Mineral Ósea: datos de densidad mineral ósea tomados de Elkin (1995), 32 puntos ploteados; **Índice de Secado: datos del índice tomados de De Nigris y Mengoni Goñalons (2002, 2004), 16 puntos ploteados; ***Índice de Carne: datos del índice tomados de Borrero (1990), 17 puntos ploteados; ****índice de Médula: datos del índice tomados de Mengoni Goñalons (1996, 1999), 6 puntos ploteados; *****índice de Médula Insaturada: datos del índice tomados de Morin (2007), 13 puntos ploteados.

Los resultados obtenidos de la correlación entre el MAU\% y el índice de densidad mineral ósea indican que solo en los parapetos 27 y 10 se ha registrado una relación positiva, moderada y estadísticamente significativa (tabla 7). Por lo tanto, es factible en ambos casos la influencia de procesos densitodependientes en la formación de los conjuntos. El resto de las muestras presentan correlaciones muy bajas, incluso negativas en el parapeto 24. Adicionalmente, no se observan diferencias marcadas entre la representación de extremos proximales/distales de húmero y tibia en cada conjunto óseo; aunque sí se reconoce una leve tendencia hacia una mayor representación de segmentos articulares distales, especialmente en el parapeto 6. Por otra parte, la selección de elementos en base a su contenido de carne solo puede ser inferida en el parapeto 24 donde se ha obtenido una correlación, aunque muy baja, estadísticamente significativa con el índice correspondiente (tabla 7). Por otra parte, en todas las estructuras se obtuvo una relación negativa y estadísticamente significativa con el índice de secado (tabla 7), sugiriendo que los elementos que mayor potencialidad tienen para ser secados no se encuentran en los conjuntos. Este resul- 
tado tiene sentido si se considera que en todas las estructuras existe una subrepresentación del esqueleto axial, segmento que exhibe mayor aptitud para el procesamiento mediante este tipo de técnica. Finalmente, con respecto a los índices de médula y médula insaturada, solo se observa una correlación estadística negativa, baja y significativa entre el primero de estos y el MAU\% del parapeto 24 (tabla 7). Este resultado indica una escasa presencia de los elementos con mayor contenido medular.

\section{Evidencias de procesamiento}

Las evidencias de procesamiento han sido registradas en todos los conjuntos óseos considerados. Las frecuencias obtenidas se distribuyen en un rango que oscila entre un $14 \%$ y un $26 \%$ del NISP, indicando la existencia de cierto grado de variabilidad. Estas proporciones, bajas-moderadas, son esperables en sitios donde el procesamiento inicial de las carcasas pudo haber cumplido un rol muy importante dentro de las tareas desarrolladas. Como se indica en la tabla 8, las estructuras que conforman el sitio K116 exhiben una distribución homogénea, próxima al 23\%, exceptuando el parapeto 24 cuyo porcentaje es sensiblemente menor. Por otra parte, en K205, el parapeto 6 presenta frecuencias muy similares a los restantes conjuntos óseos de la meseta, mientras que, por el contrario, la estructura 10 exhibe el valor más bajo registrado para toda la muestra.

Tabla 8. Evidencias de procesamiento registradas en los conjuntos óseos

\begin{tabular}{|c|c|c|c|c|c|c|c|c|c|c|c|c|}
\hline & \multicolumn{2}{|c|}{ Parapeto 27 } & \multicolumn{2}{|c|}{ Parapeto 38 } & \multicolumn{2}{c|}{ Parapeto 11 } & \multicolumn{2}{c|}{ Parapeto 24 } & \multicolumn{2}{c|}{ Parapeto 6 } & \multicolumn{2}{c|}{ Parapeto 10 } \\
\cline { 2 - 16 } & NISP & NISP\% & NISP & NISP\% & NISP & NISP\% & NISP & NISP\% & NISP & NISP\% & NISP & NISP\% \\
\hline Corte & 2 & 2,9 & 30 & 7,9 & 52 & 13,4 & 9 & 7,9 & 29 & 6,6 & 8 & 4,4 \\
\hline Percusión & 9 & 13,0 & 36 & 9,5 & 36 & 9,3 & 5 & 4,4 & 47 & 11 & 14 & 8 \\
\hline $\begin{array}{c}\text { Corte- } \\
\text { Percusión }\end{array}$ & 5 & 7,2 & 18 & 4,8 & 14 & 3,6 & 4 & 3,5 & 26 & 6 & 3 & 2 \\
\hline Total & 16 & 23,2 & 84 & 22,2 & 102 & 26,3 & 18 & 15,8 & 103 & 23,4 & 25 & 14 \\
\hline
\end{tabular}

Los daños antrópicos registrados refieren tanto a marcas de corte como de percusión (tabla 8). Si bien con cierto grado de variación en cada caso en particular, ambas actividades presentan un peso equilibrado en las estrategias de procesamiento de cada uno de los conjuntos óseos. La única excepción es el parapeto 27, en donde las incisiones exhiben valores muy bajos; aspecto posiblemente ligado con su procedencia superficial y la operatoria de agentes tafonómicos específicos (por ej. meteorización). Como se detalla en la tabla 8, los parapetos 27 y 38 exhiben una mayor relevancia de las actividades de percusión, mientras que las estructuras 11 y 24 registran más incidencia de tareas vinculadas con el corte. Este resultado indica que en el sitio K116 la importancia de cada tarea parece haber sido diferencial en el espacio pero, a su vez, complementaria dentro de las estrategias de procesamiento. Por otra parte, para K205 no se observan diferencias significativas entre ambos conjuntos. Las evidencias de percusión presentan valores más elevados, especialmente en el parapeto 10 .

Las marcas de corte, salvo en el parapeto 10, se localizan con mayor frecuencia en el esqueleto axial, esto es especialmente evidente en la estructura 11 de K116. En todos los conjuntos considerados, las incisiones se ubican, principalmente, en la columna vertebral (vértebras torácicas, lumbares y cervicales, en ese orden), las costillas y la pelvis. El análisis específico de las características y ubicación de los daños identificados permite sugerir su estrecha vinculación con 
el desarrollo de tareas de descarne, desarticulación y evisceración de las carcasas. En el esqueleto apendicular, las marcas se identifican preferentemente en extremidades superiores, medias y falanges primeras. En general, se asocian con el desarrollo de tareas de desarticulación y descarne, actividades ligadas con el aprovechamiento de carne, la reducción de las carcasas y la preparación de los elementos para su posterior fracturación.

Las evidencias de percusión identificadas incluyen negativos de impacto, lascas adheridas, estrías y hoyos de percusión. Fueron registradas en su gran mayoría en el segmento apendicular, con muy baja presencia en el esqueleto axial, asociadas únicamente con la fracturación de vértebras y costillas. Concretamente, se concentran en falanges, extremidades medias (radioulna y tibia) e inferiores (metacarpos, metatarsos y metapodios). Es evidente que los huesos preferentemente fracturados son aquellos que presentan buen contenido de médula ósea y ácidos grasos no saturados. De acuerdo con los rasgos de percusión determinados, es posible sugerir la implementación de diversos métodos de fractura en los conjuntos (por ej. percutor y yunque, yunque estático y hueso móvil). Entre éstos se destaca la presencia de marcado perimetral/fractura transversa, técnica registrada en la mayoría de las estructuras, pero especialmente frecuente en los parapetos 6 y 10 de K205.

La presencia de especímenes termoalterados se limita solo a dos estructuras, parapetos 11 y 24, ambos correspondientes al sitio K116. El porcentaje de huesos alterados térmicamente en cada caso es muy bajo. Es interesante destacar que en la mayoría de los fragmentos también se identificaron evidencias de procesamiento. Nuevamente, estos resultados son esperables en sitios en donde las actividades de obtención de presas y su procesamiento inicial habrían sido prioritarias. En estos contextos, el uso del fuego es complementario dado que las actividades de consumo, principalmente en términos de snack, incluyen el aprovechamiento de partes que no requieren de una cocción prolongada (Yellen 1977; Binford 1978; Bunn et al. 1988, O'Connell et al. 1992; entre otros).

\section{DISCUSIÓN Y CONCLUSIONES}

Como ha sido señalado al principio de este trabajo, los datos presentados representan la primera información zooarqueológica sistemática para la meseta del Strobel. En este marco, se consideró necesario discutir las principales problemáticas arqueofaunísticas de la meseta en esta instancia. En primer lugar, determinar los procesos tafonómicos involucrados en la formación de los conjuntos óseos y, en segundo lugar, caracterizar las estrategias de utilización de los recursos faunísticos implementadas en el área durante el Holoceno tardío.

La cantidad de sitios arqueológicos registrados en la meseta del Strobel es alta. Se estima que, hasta la actualidad y luego de 18 años de trabajos de campo sistemáticos, ha sido posible prospectar un poco más del $25 \%$ de la superficie total del área. En este contexto, más de 220 sitios han sido identificados incluyendo estructuras de parapetos, conjuntos localizados en paredones basálticos y distribuciones superficiales de materiales arqueológicos (Re et al. 2017). A pesar de esta elevada cifra, hasta el momento, únicamente los sitios presentados en este trabajo exhiben evidencias zooarqueológicas. Es probable que esta situación se encuentre, al menos en parte, sujeta a la incidencia de procesos postdepositacionales específicos que configuran un paisaje en el interior del área donde existen espacios más o menos conservativos de restos óseos.

Como hemos mencionado, la probabilidad de registrar evidencia zooarqueológica en sitios asociados a paredones basálticos son bajas (Belardi et al. 2007). En estos sectores, las características químicas de los sedimentos, la alternancia de humedad y la percolación del agua generada por el derretimiento de la nieve en primavera establecen ambientes poco favorables para la preservación ósea (Belardi et al. 2007). Aún en la actualidad, el hallazgo de huesos en 
excavaciones estratigráficas realizadas en estos sectores continúa otorgando resultados negativos, lo que sostiene la validez de la hipótesis diagenética propuesta. En contraste, los depósitos arqueológicos recuperados en algunas estructuras de parapetos, sitios en espacios abiertos y con gran incidencia del viento del oeste, exhiben una importante cantidad de evidencia zooarqueológica. Como ha sido detallado en este trabajo, los conjuntos óseos presentan un estado de preservación muy similar. En promedio, la presencia de agua y/o la alternancia de humedad no parecen ser factores de peso en la formación de los conjuntos. En cambio, la meteorización es el agente natural que mayor incidencia ha tenido en cada una de las muestras. Los perfiles reconstruidos indican una tendencia homogénea entre todos los casos, en donde la mayoría de los especímenes óseos se concentran en estadios maduros (estadios 2 y 3 ), sugiriendo una operatoria moderada de este agente. No obstante, la presencia de huesos, en baja frecuencia, en instancias más avanzadas, advierte que la existencia de pérdida ósea es probable, en algunos casos con mayor magnitud que otros (ej. parapeto 27). En este sentido, se debe mencionar que las particularidades microlocales de cada conjunto, asociadas con la presencia/ausencia de vegetación, las características del parapeto (morfología, tamaño, altura de la pared, entre otras) y el nivel de exposición del sustrato basáltico de la meseta pueden condicionar tempranamente el potencial de preservación de un conjunto. En algunos casos, como los presentados en esta oportunidad, la pared de la estructura funciona como una trampa de sedimento que facilita el enterramiento y conservación de los restos óseos que se disponen entre sus rocas y/o debajo de ellas. Por otra parte, la ausencia de evidencia faunística en estructuras no siempre puede encontrarse atada a problemas de preservación. Existen factores funcionales asociados exclusivamente con su uso en el pasado; no todos los parapetos tuvieron un rol estrictamente vinculado con el procesamiento, consumo y descarte de huesos. Como ha sido descripto en casos etnográficos, diferentes estructuras cumplen distintos roles dentro de una estrategia de caza por emboscada. Así, algunas solo son utilizadas para monitorear el comportamiento de las presas y/o para guiar los animales hacia los sectores de matanza (Binford 1991; Grønnow 2009).

En síntesis, las condiciones de preservación ósea parecen ser diferenciales al interior del espacio local. Consistentemente con lo sugerido por Belardi et al. (2007), las posibilidades de registrar evidencias zooarqueológicas en la meseta del Strobel aumenta fuera de los paredones rocosos, sectores donde se ubican muchos sitios arqueológicos protegidos de los fuertes vientos del oeste, pero conservativos de carga nival hasta entrada la primavera. En consecuencia, por el momento, las estructuras de parapetos pueden ser los espacios más conservativos del área; patrón que probablemente se repita en otros plateaus basálticos de la región. A pesar de la alta exposición de los materiales al deterioro ambiental, las mesetas conservan conjuntos representativos de todo tipo de actividades ligadas con el manejo de la fauna.

La información arqueológica disponible para la meseta del Strobel sugiere que habría sido un espacio utilizado logística y/o estacionalmente durante los últimos 2500 años AP. La evidencia zooarqueológica presentada en este trabajo es consistente con esta propuesta. Tanto en K116 como en K205 el desarrollo de actividades vinculadas con la obtención de presas, su procesamiento inicial, transporte y consumo diferido parecen haber sido tareas prioritarias. En este sentido, como se detalló en la sección anterior, los conjuntos óseos recuperados en cada estructura de ambos sitios se encuentran muy incompletos y presentan un claro desbalance entre elementos axiales y apendiculares, en favor de estos últimos. Asimismo, las evidencias de procesamiento identificadas exhiben valores bajos-moderados. Además, la extensión de la fragmentación ósea es reducida y la existencia de elementos alterados térmicamente es escasa, limitada solo a dos estructuras de parapetos. De este modo, más allá del grado de variación relativa al funcionamiento específico de cada estructura y a la incidencia en cada caso de procesos de destrucción diferencial, esta configuración del registro posiblemente se encuentre ligada con instancias iniciales de reducción de presas y la influencia del transporte de partes anatómicas. Estos resultados establecen también la existencia 
de una serie de semejanzas entre los conjuntos considerados, aspecto que posiblemente se deba al peso del comportamiento logístico y/o estacional involucrado en la ocupación de la meseta.

La información presentada también indica la presencia de variabilidad en las características zooarqueológicas registradas entre ambos sitios, así como también en el interior de cada uno de ellos. En referencia a la distribución de partes anatómicas, las diferencias principales se vinculan con la presencia e importancia de porciones óseas específicas en cada conjunto. En el sitio K116 existe una tendencia general hacia una mayor representación de elementos de escaso contenido nutricional. Esta es una evidencia especialmente clara en los parapetos 38 y 11, donde las tareas de descarte parecen haber focalizado en huesos de una utilidad marginal. Sin embargo, en el parapeto 24 este patrón no resulta tan evidente. En este caso, elementos de mayor rinde económico como vértebras, escápula, radioulna, fémur y tibia exhiben frecuencias elevadas. Este mismo contraste también ha sido identificado en otras variables zooarqueológicas en este sitio como la cantidad mínima de individuos representados, el porcentaje de especímenes inmaduros, la relevancia de las actividades de corte o percusión dentro de las estrategias de procesamiento y la presencia de elementos alterados térmicamente. Estas diferencias ponen de relieve la existencia de variabilidad en el sitio. De este modo, si bien las actividades llevadas a cabo se encuentran estrechamente vinculadas con la obtención y procesamiento inicial de presas, las tareas involucradas pudieron haber sido diversas y/o estar segregadas espacialmente. El análisis de la tecnología lítica es consistente con este planteo, sugiriendo la presencia de una distribución diferencial en el espacio de puntas de proyectil y raspadores, instrumentos más frecuentes en el sitio (Dellepiane y Flores Coni 2014; Goñi et al. 2014; Flores Coni 2018). Por otra parte, en K205 las características zooarqueológicas registradas en los parapetos 10 y 6 difieren entre sí en varios puntos (cantidad mínima de individuos representados, perfiles de partes anatómicas y frecuencia de evidencias de procesamiento). En este caso, dado que ambas estructuras exhiben una señal cronológica diferente, es posible sugerir que la reocupación del sitio pudo haber admitido la implementación de estrategias variables en relación con el manejo de la fauna a lo largo del tiempo. Es así que, si bien para ambos conjuntos es defendible el desarrollo de tareas de caza y procesamiento inicial de presas, las modalidades establecidas pudieron ser potencialmente distintas.

Desde una escala de análisis más amplia, los sitios considerados en este trabajo presentan diferencias marcadas en relación con una serie de aspectos como su estructuración en el espacio, la cantidad y características de los parapetos que los conforman, la cronología y la composición y diversidad de la tecnología lítica recuperada. En referencia al registro faunístico, muchos de los resultados que han sido presentados en este trabajo también indican la existencia de contrastes entre ambos sitios. Es posible entonces sugerir que parte de estas diferencias pueden corresponderse con el desarrollo de alternativas variables en relación con las tácticas y técnicas de obtención de presas implementadas en la meseta a lo largo del tiempo y en el espacio, en el marco de contextos ambientales y sociales particulares. En este sentido, en K116 se observa una elevada presencia de animales representados. La información cronológica disponible para el sitio permite considerar que al menos algunas de sus estructuras pudieron haber funcionado sincrónicamente en el pasado. Además, su configuración arqueológica, en especial la excepcional cantidad de parapetos agrupados en un espacio acotado y la elevada presencia de puntas de proyectil ( $\mathrm{N}=200)$ son elementos que lo distinguen de otros sitios, no solo en la meseta, sino también en la región. En conjunto, estas evidencias permiten considerar la existencia de eventos de caza específicos, ligados a la obtención de múltiples animales bajo una modalidad de tipo comunal y/o masiva (Goñi et al. 2016; Dellepiane 2019; Flores Coni 2019; Flores Coni et al. 2021). Por el momento, la evidencia disponible en K205 indica un escenario diferente. Por un lado, la cantidad de animales representados es más restringida y por otro, no es posible sostener la penecontemporaneidad de las muestras. Estas diferencias podrían indicar la existencia de variabilidad en relación con las tácticas de obtención de presas implementadas en la meseta. 
La meseta del Strobel habría sido un espacio plenamente incorporado a la dinámica de las poblaciones humanas de la región para los últimos 2500 años AP, evidenciando una notable intensificación de su uso y una marcada redundancia ocupacional para los últimos 1300 años AP. A lo largo de este período, su utilización, lejos de exhibir un uso logístico homogéneo y estático, se caracteriza por el desarrollo de estrategias que pudieron ser altamente variables, compuestas por alternativas múltiples. A medida que el Holoceno tardío avanza, la ocupación efectiva del área se vuelve cada vez más sostenida, planificada y variable (Cassiodoro et al. 2016; Goñi et al. 2016; Re et al. 2017; Guichón 2018; Dellepiane 2019; Flores Coni 2019; Flores Coni et al. 2021; entre otros). En este marco, el desarrollo de estrategias tecnológicas específicas, como la construcción de parapetos y su equipamiento con instrumentos líticos, núcleos y lascas, representa un aspecto clave para comprender su uso progresivo al menos durante los últimos 2000 años AP (Flores Coni et al. 2021).

Las estructuras representan el único tipo de reparo antrópico en la meseta. Hasta la actualidad se han registrado más de 368 parapetos localizados en distintos sectores del área; cifra excepcional en la región y en Patagonia. En la meseta del Strobel, y en los alrededores, representan una tecnología característica del Holoceno tardío, asociada, principalmente, con el desarrollo de actividades de caza. El acomodamiento del ambiente con estructuras que revisten un carácter perdurable indica el equipamiento de lugares que serán recurrentemente utilizados. De este modo, los espacios son provistos de recursos específicos, en este caso parapetos, con el objeto de anticiparse a futuras necesidades (Binford 1979). Como señalan Flores Coni y coautores (2021), la construcción de estructuras en el área se incrementa de manera aditiva a lo largo del Holoceno tardío configurando un paisaje arqueológico dotado de la tecnología adecuada para establecer, señalar y reclamar territorios de caza. Así, determinados espacios, en este caso la meseta, se jerarquizan como puntos estratégicos en la circulación cazadora regional y se establecen como sectores que garantizan un elevado retorno energético y social bajo un costo que disminuye con el paso del tiempo (Flores Coni et al. 2021). Claro está que la redundancia ocupacional de un determinado lugar no implica necesariamente que su utilización sea homogénea o estandarizada. En este sentido, las estrategias de equipamiento tecnológico permiten que su uso sea variable a lo largo del tiempo en función de los cambios ambientales, climáticos o sociales que puedan ocurrir (Flores Coni et al. 2021).

De acuerdo con la información presentada en este trabajo, las tareas de obtención de presas, procesamiento inicial y posiblemente el transporte de partes anatómicas han representado una gran parte de las actividades desarrolladas en torno al manejo de la fauna en la meseta. No obstante, las modalidades implementadas pudieron ser altamente variables en el tiempo y en el espacio. Esta afirmación no solo deriva de las diferencias registradas en los conjuntos óseos considerados, sino también de la elevada diversidad propia de este tipo de sitio en relación con sus características generales, ubicación, emplazamiento topográfico, grado de asociación (estructuras aisladas o en conjunto) y presencia/ausencia, frecuencia y densidad de materiales arqueológicos asociados. En conjunto la información disponible puede ser indicativa de la existencia de una gran variedad de estrategias alternativas en referencia al uso de estructuras y su relación con las tácticas de procuración de presas. En este sentido, es probable que una gran parte de las estructuras registradas en la meseta se encuentren asociadas con eventos de caza de pocos animales, o parapetos que en algunos casos solo fueron utilizados de manera esporádica en relación con tareas puntuales como el monitoreo de presas, bajo contextos muy logísticos y específicos. Pero también, otros pudieron estar ligados con un mayor tiempo de uso y redundancia ocupacional; inclusive, algunos casos, pudieron incluir instancias de caza de múltiples animales en el contexto de una modalidad de tipo comunal y/o masiva. Adicionalmente, la variabilidad asociada con el manejo de la fauna puede ser aún mayor, en tanto que tareas específicas pudieron encontrarse segregadas en el espacio local. Es decir, actividades vinculadas con instancias más intensivas de procesamiento, consumo, el desarrollo de tareas particulares como la preparación de cueros y/o la producción de grasa ósea 
pudieron ser llevadas a cabo en torno a sectores con reparo natural y agua como los paredones basálticos. El registro arqueológico (representaciones rupestres y tecnología lítica) admite considerar que un uso habitacional podría ser esperable en estos espacios. Al respecto, la presencia de huesos en estos sectores no ha sido registrada aún, consecuencia de la operatoria de procesos postdepositacionales (Belardi et al. 2007), aspecto que ya hemos discutido.

En síntesis, este trabajo representa la primera información zooarqueológica sistemática para la meseta del Strobel y establece su incorporación a las discusiones arqueofaunísticas regionales. Los resultados que han sido presentados, consistentes con el modelo general de poblamiento, indican que la ocupación de la meseta manifiesta un marcado carácter logístico y/o estacional, posiblemente articulado desde sectores altitudinalmente bajos. En este marco, las actividades de subsistencia desarrolladas han estado focalizadas en la obtención y reducción inicial de presas en vías de su transporte y consumo diferido en el tiempo y en el espacio. Dentro de este escenario, ha sido registrado un amplio rango de variabilidad. Así, la utilización del área, lejos de exhibir un uso homogéneo y estático se fundamenta en el desarrollo de estrategias variables caracterizadas por alternativas y modalidades múltiples. Es importante destacar que la totalidad del registro óseo considerado procede de estructuras de parapetos, sitios en los cuales este tipo de evidencia no suele encontrarse disponible. Por lo tanto, se considera que la información que ha sido presentada constituye un aporte novedoso y significativo para la arqueología de Santa Cruz y de Patagonia en general.

\section{AGRADECIMIENTOS}

Las investigaciones fueron subsidiadas por los proyectos PIP CONICET 0122, UBACyT

W 441 PICT 2012-1352, PICT 201-0373 y el Ministerio de Cultura de la Nación. Los valiosos comentarios de Rafael Goñi, Josefina Flores Coni y Francisco Guichón ayudaron a mejorar significativamente este trabajo. Por último, se agradece especialmente los comentarios y sugerencias realizadas por los doctores Eduardo Moreno y Federico Scartascini.

\section{BIBLIOGRAFÍA}

Behrensmeyer, A. K

1978. Taphonomic and ecologic information from bone weathering. Paleobiology 4: 150-162.

Belardi, J. B., M. Bregliani, D. Rindel, T. Bourlot y H. Gómez

2007. Condiciones de preservación de conjuntos arqueofaunísticos en la meseta del Strobel (provincia de Santa Cruz, Argentina). En F. Morello, M. Martinic, A. Prieto y G. Bahamonde (eds.), Arqueología de Fuego-Patagonia. Levantando piedras, desenterrando huesos...y develando arcanos: 411-420. Punta Arenas. CEQUA.

Belardi, J. B. y R. A. Goñi

2006. Representaciones rupestres y convergencia poblacional durante momentos tardíos en Santa Cruz (Patagonia argentina). El caso de la meseta del Strobel. En D. Fiore y M. M. Podestá (eds.), Tramas en la Piedra: 85-94. Buenos Aires. WAC, SAA y AINA.

Binford, L.

1978. Nunamiut Ethnoarchaeology. New York. Academic Press.

1979. Organization and formation processes: looking at curated technology. Journal anthropological research 398 Res 35(3): 255-273.

1981. Bones: Ancient Men and Modern Myths. New York. Academic Press. 
1991. A corporate caribou hunt. Expedition 33 (1): 33-43.

2001. Constructing Frames of Reference. An Analytical Method for Archaeological Theory Building Using Ethnographic and Environmental Data Sets. Berkley, Los Angeles y Londres. University of California Press.

Borrero, L.

1990. Fuego-Patagonian Bone Assemblages and the Problem of Communal Guanaco Hunting. En L. B. Davis y B. O. K. Reeves (eds.), Hunters of the Recent Past: 373-399. London. Unwin Hyman.

Bunn, H. T., L. E. Bartram y E. M. Kroll

1988. Variability in bone assemblage formation from hadza hunting, scavenging, and carcass processing. Journal of Anthropological Archaeology 7: 412- 457.

Cassiodoro, G.

2011. Movilidad y uso del espacio de cazadores-recolectores del Holoceno tardío: estudio de la variabilidad del registro tecnológico en distintos ambientes del noroeste de la provincia de Santa Cruz. South American Archaeology Series 13, British Archaeological Reports (International Series), Oxford, Archaeopress.

Cassiodoro, G., R. Goñi y S. Pasqualini

2016. Variabilidad del registro arqueológico en sectores altos de Santa Cruz: tendencias generales en el uso del espacio. En F. Mena (ed.), Arqueología de la Patagonia de mar a mar: 224-234. Coyhaique. CIEP-Ñire Negro ediciones.

Dalton, K.

2011. A geospatial analysis of prehistoric hunting blinds and forager group size at Cowhead Slough, Modoc County, California. Tesis de Maestría inédita. Faculty of California State University.

Dellepiane, J.

2018. Uso de imágenes satelitales para el reconocimiento de parapetos en el centro oeste de Patagonia meridional. Arqueología 24 (2): 1-11.

2019. Poblamiento y uso del espacio en sectores mesetarios del centro-oeste de Santa Cruz durante el Holoceno tardío. Una aproximación zooarqueológica. Tesis doctoral inédita, Facultad de Filosofía y Letras, Universidad de Buenos Aires.

Dellepiane, J. y J. Flores Coni

2016. Aspectos tecnológicos y faunísticos en sitios a cielo abierto: variabilidad del registro en los parapetos de la meseta del Strobel, Provincia de Santa Cruz. En F. Mena (ed.), Arqueología de la Patagonia: de mar a mar: 245-255. Coyhaique, CIEP-Ñire Negro ediciones.

De Nigris, M. E.

2003. Procesamiento y consumo de ungulados en contextos arqueológicos de Patagonia Meridional: el caso de Cerro Casa de Piedra Cueva 7. Tesis doctoral inédita. Facultad de Filosofía y Letras, Universidad de Buenos Aires.

De Nigris, M. E. y G. L. Mengoni Goñalons

2002. The guanaco as a source of meat and fat in the southern Andes. En J. Mulville y A. Outram (eds.),

The Zooarchaeology of Milk and Fats: 160-166. Barnsley. Oxbow Books.

Dincauze, D.

2000. Environmental Archaeology, Principles and Practices. Cambridge. Cambridge University Press.

Elkin, D. C.

1995. Volume density of South American camelids skeletal parts. International Journal of Osteoarchaeology 5 (1): 29-57. 
Fisher, L. B.

1995. Bone surface Modifications in Zooarchaeology. Journal of Archaeological Method and Theory 2 (1): 7-68.

Flores Coni, J.

2018. Poblamiento humano y uso del espacio en la meseta del Strobel (provincia de Santa Cruz). Un análisis sobre la variabilidad tecnológica durante el Holoceno. Tesis doctoral inédita. Facultad de Filosofía y Letras, Universidad de Buenos Aires.

2019. Tecnología de parapetos en Patagonia meridional: El caso de la meseta del Strobel. Relaciones de la Sociedad Argentina de Antropología 44(1): 131-153.

Flores Coni, J., J. Dellepiane., G. Cassiodoro., R. Goñi y A. Agnolin

2021. Technological Strategies and Guaranteed Return: Hunting Blinds and Patagonic Plateaus. En: J.

B. Belardi, D. Bozzuto, P. M. Fernández, E. Moreno y G. Neme (eds.), Ancient hunting strategies in southern South America: 293-312. Cham, Switzerland. Springer AG.

Franklin, W. L.

1982. Biology, Ecology, and Relationship to Man of the South American Camelids. En M. A. Mares y H. H. Genoways (eds.), Mammalian Biology in South America. Vol. 6: 457-489. Special Publication Series. Pittsburgh. University of Pittsburgh.

1983. Contrasting Socioecologies of South America's Wild Camelids: The Vicuña and the Guanaco. En J. F. Eisenberg y D. G. Kleiman (eds.) Advances in the Study of Mammalian Behavior: 573-679. Shippensburg. The American Society of Mammalogy. Special Publication 7.

Frison, G.

1978. Prehistoric Hunters of the High Plains. New York. Academic Press.

Goñi, R.

2010. Cambio climático y poblamiento humano durante el Holoceno tardío en Patagonia meridional Una perspectiva arqueológica. Tesis doctoral inédita. Facultad de Filosofía y Letras, Universidad de Buenos Aires.

Goñi, R., G. Cassiodoro, J. Flores Coni, J. Dellepiane, A. Agnolin y R. Guichón Fernández

2016. Estrategias de caza y movilidad. Parapetos del sitio K116 (Meseta del Strobel, Santa Cruz). En: F. Mena (ed.), Arqueología de Patagonia: de Mar a Mar: 441-449. Coyhaique. CIEP/Ñire Negro ediciones.

Goñi, R. A., A. Re, J. B. Belardi, J. Flores Coni y F. Guichón

2014. Un lugar muy particular. Caza, convergencia de poblaciones y circulación de información en la meseta del Strobel. En R. Goñi, J. Belardi, G. Cassiodoro y A. Re (eds.), Arqueología de los lagos Cardiel y Strobel. Poblamiento humano y paleoambientes en Patagonia: 155-186. Buenos Aires, Aspha Ediciones.

Gradin, C.

1959-60a. Petroglifos de la meseta del lago Strobel (prov. de Santa Cruz, Argentina). Acta Praehistorica III/IV: $123-143$.

1959-60b. Tres informaciones referentes a la meseta del Lago Strobel (Prov. de Santa Cruz, Argentina). Acta Praehistorica III-IV: 144-149.

Grønnow, B.

2009. Caribu hunting structures and hunting grounds of the Thule Culture in Angujaartorfiup Nunaa, West Greenland. En B. Grønnow (ed.), On the thack of the Thule Culture from Bering strart to east Greenland. Proceedings of the Sila Conference: 201-210. Denmark. National Museum. 
Guichón, F.

2018. Redes de información durante el Holoceno medio y tardío en Patagonia meridional. Estudio de las representaciones rupestres en la cuenca del lago Cardiel y el sur de la meseta del Strobel. Tesis doctoral inédita. Facultad de Filosofía y Letras, Universidad de Buenos Aires.

Gutiérrez, M. A.

2004. Análisis tafonómicos en el Área Interserrana (provincia de Buenos Aires). Tesis doctoral inédita. Facultad de Ciencias Naturales y Museo, Universidad Nacional de La Plata.

Gutiérrez, M., M. González, M. C. Álvarez, A. Massigoge y C. Kaufmann 2016. Meteorización ósea en restos de guanaco y ñandú. Arqueología 22: 57-84.

Klein, R. G. y K. Cruz-Uribe 1984. The analysis of animal bones from archaeological sites. Chicago. University of Chicago Press.

Lancelotti, J.

2009. Caracterización limnológica de lagunas de la Provincia de Santa Cruz y efectos de la introducción de Trucha Arco iris (Oncorhyn chusmykiss) sobre las comunidades receptoras. Universidad Nacional del Comahue, Bariloche. Ms.

León, R., D. Bran, M. Collantes, J. Paruelo y A. Soriano

1998. Grandes unidades de vegetación en la Patagonia extra andina. Ecología Austral 8: 125-144.

Lyman, R. L.

1994. Vertebrate Taphonomy. Cambridge. Cambridge University Press.

Lupo, K.

2001. On the archaeological resolution of body part transport patterns: An ethnoarchaeological example from East African hunter-gatherers. Journal of Anthropological Archaeology 20: 361-378.

Malouf, C.

1961. The Tipi Rings of the High Plains. American Antiquity 26 (3): 381-389.

Mengoni Goñalons, G. L.

1999. Cazadores de guanacos de la estepa patagónica. Buenos Aires. Sociedad Argentina de Antropología.

Morin, E.

2007. Fat composition and Nunamiut decision-making: a new look at the marrow and bone grease indices. Journal of Archaeological Science 34: 69-82.

Nuevo Delaunay, A.

2015. Transformación del paisaje arqueológico rural en el centro oeste de la provincia de Santa Cruz, siglo XX. Tesis doctoral inédita. Facultad de Filosofía y Letras, Universidad de Buenos Aires.

O’Connell, J. F., K. Hawkes y N. Blurton Jones

1992. Patterns in the Distribution, Site Structure and Assemblage Composition of Hadza Kill- Butchering Sites. Journal of Archaeological Science 19: 319-345.

Pacheco Torres, V., Altamirano y E. Guerra Porras

1979. Guía osteológica de camélidos sudamericanos. Lima. Universidad Nacional Mayor de San Marcos.

Gabinete de Arqueología, Colegio Real.

Paruelo, J., A. Beltrán, E. Jobbágy, O. Sala y R. Golluscio

1998. The climate of Patagonia: general patterns and controls on biotic processes. Ecología Austral 8: 85-101. 
Re, A.

2010. Circulación de información en espacios de uso estacional: grabados de mesetas altas de Santa Cruz. Tesis doctoral inédita. Facultad de Filosofía y Letras, Universidad de Buenos Aires.

Re, A., R. Goñi, J. Flores Coni, F. Guichón, J. Dellepiane y M. Umaño

2017. La meseta del Strobel (Patagonia Meridional): 15 años después. Relaciones de la Sociedad Argentina de Antropología 42 (1): 133-158.

Rindel, D. D.

2009. Arqueología de momentos tardíos en el noroeste de la Provincia de Santa Cruz (Argentina): una perspectiva faunística. Tesis doctoral inédita. Facultad de Filosofía y Letras, Universidad de Buenos Aires. 2013. Marcos de referencia y frecuencia de partes esqueletarias de guanaco en sitios de Patagonia meridional: el caso del Índice de Médula Insaturada. En A. Zangrando, R. Barbarena, A. Gil, G. Neme, M. Giardina, L. Luna, C. Otaola, S. Paulides, L. Salgán y A. Tivoli (comps.), Tendencias teórico-metodológicas y casos de estudio en la Patagonia: 515-522. San Rafael, Museo de Historia Natural de San Rafael.

Sierpe, V. G.

2015. Atlas osteológico del guanaco (Lama Guanicoe). PuntaArenas. Ediciones Universidad de Magallanes.

Stine, S.

1994. Extreme and persistent drought in California and Patagonia during mediaeval time. Nature, vol. 369: 546-549.

Stine, S. y M. Stine

1990. A record from Lake Cardiel of Climate Change in Southern America. Nature 345(6277): 705-708.

Yellen, J.

1977. Cultural Pattern in Faunal Remains: Evidence from the !Kung Bushman. En D. Ingersoll, J. Yellen y W. Macdonald (eds.), Experimental Archaeology: 271-331. New York. Columbia University Press. 
